\title{
Modeling Senior Travelers' Acceptance of New Transit Systems
}

\author{
Mohamed A. Abdel-Aty \\ University of Central Florida
}

\section{Abstract}

This article examines the findings of an investigation of senior travelers ' willingness to use several advanced transit systems. Elderly travelers were surveyed to evaluate their acceptance of a real-time paratransit and several transit information systems. The likelihood of using each system was estimated using the binary probit modeling methodology. The analysis showed that gender, income, age, type of trips recently made, and several perception-related variables are among the factors that affect the decision to accept the new transportation systems. The study also showed the important potential of several transportation technologies to increase the mobility and alleviate the transportation difficulties of the elderly population. In addition, the results illustrated the willingness of many groups of senior travelers to use new transportation systems in an attempt to reduce their travel problems.

\section{Introduction}

The elderly are a rapidly growing segment of the U.S. population. The 1990 census shows that individuals more than 65 years old constitute 12.6 percent of the population, and that this segment continues to grow. The Nationwide Personal Transportation Survey (NPTS) shows that although today's elderly 
rely more on the automobile than in the past, individuals more than 75 years old experience driving difficulties that lead to a decline in their mobility, and are looking for alternative transportation modes (U.S. Department of Transportation 1992; Transportation Research Board 1988).

In a paper by Abdel-Aty and Jovanis (1998), a survey of elderly travelers in California was introduced. The survey showed that the elderly are taking, and are willing to take, many trips for different purposes. The results also uncovered many problems and difficulties experienced by the elderly, which oftenlead to missing some important trips such as medical appointments.

Intelligent Transportation Systems (ITS), particularly those tailored to meet the needs of elderly travelers dealing with transit and paratransit, are envisioned as potential solutions for the elderly's improved mobility and the reduction of their transportation-related problems.

Not much is available in the literature about the elderly's acceptance of new technologies. Geehan and Suen (1993) explored the acceptance of Advanced Traveler Information Systems (ATIS) by the elderly and disabled. They found that special groups generally prefer in-vehicle information systems over both pretrip and in-terminal information. Suen and Parviainen (1993) discussed a conceptual framework of advanced travel accessibility systems for the elderly and disabled. Suen and Rutenberg (1994) reviewed the ATIS in Canadian transportation terminals. Guthrie and Phillips (1994) discussed the market opportunities of ITS for elderly and disabled travelers. Schweiger and McGrane (1994) reviewed the different Advanced Public Transportation Systems (APTS) that could directly and indirectly affect elderly and disabled travelers. They also addressed the challenges for developing and implementing APTS for the elderly and disabled. Although most of these studies noted that the private vehicle is the most favored transportation mode for the elderly, they indicated that satisfying the informational requirements of the elderly is very important, and that the demand for pretrip and en route information systems for the elderly continues to grow. Although many previous studies have addressed the elderly's travel behavior and mobility (e.g., Witkowski and Buick 1985), or estimated models of mode choice or demand for public transportation by senior 
citizens (Parolin 1988; Lago and Burkhardt 1980), very limited research has attempted to estimate models of the elderly's acceptance of advanced transportation systems.

This article presents models of the elderly's willingness to use transit or paratransit given the availability of several new transportation systems. The data used in this modeling effort were collected using a Computer-Aided Telephone Interview (CATI). Abdel-Aty and Jovanis (1998) describe in detail the CATI survey, general descriptive statistics of the sample group, physical capabilities of the elderly, and their travel characteristics.

\section{The Senior's Survey}

A CATI survey, conducted in August 1996, targeted a random sample of the elderly population in the Sacramento area in northern California. The CATI was limited to respondents 65 years old and above, and yielded a sample of 260 respondents. The main objectives of the survey were to define the characteristics and travel behavior of the elderly, and to test their acceptance of new transportation technologies and the technologies' potential for improving mobility.

The survey contained 105 questions and took 13 minutes to complete. Three callbacks were attempted to each potential respondent until the desired sample size was reached. Respondents who were unable to respond to the survey when initially contacted were offered the option of a callback at a more convenient time. Respondents who found it difficult to answer questions for a long period of time were given the opportunity to call on a toll-free number to complete the survey at their convenience.

Of the total sample group, 48.1 percent were males and 51.9 percent were females. This is very comparable to the 1990 census for the national male/female percentage more than 65 years old $(48.4 \%$ male and $51.6 \%$ female). About 23.6 percent of the sample were 65 to 69 years old; 62.8 percent, 70 to $79 ; 13.2$ percent, 80 to 89 ; only 1 respondent was in the 90 or above age category. The majority, as expected, were in the first two age categories (65 to 79 years old).

Most respondents had relatively low to middle incomes. The largest percentage, about 17.8 percent, were in the $\$ 10,000$ to $\$ 19,999$ income group; 
15.1 percent and 16.7 percent had incomes of $\$ 20,000$ to $\$ 29,999$, and $\$ 30,000$ to $\$ 39,999$, respectively. Of the total respondents, $36.4 \%$ completed some college, while 17.1 percent had a four-year college degree. Most respondents (68.6\%) were married, 19.4 percent widowed, and 12 percent were single or divorced. The majority lived in two-person households (67.1\%); the remainder (26\%) lived in one-person households.

The distribution of car ownership per household shows that the majority of the respondents owned one vehicle (48.5\%). Only 4.3 percent lived in households that did not own any vehicle. About 36.6 percent lived in households with only one licensed driver; 58.2 percent lived in households with two licensed drivers. Most respondents were retired (94.6\%). Of the 11 respondents (4.3\%) who were employed, only 5 were employed full time; the remaining 6 were employed part time. Two respondents went to school part-time.

These descriptive statistics indicate several characteristics of the elderly population. They tend to be nonworking and to have relatively low incomes. Thus, the elderly need a low-cost transportation service that is convenient and serves destinations of activities other than work (e.g., medical, recreational, etc.). Although a small percentage, some elderly neither own a car nor have a driver's license, which again indicates their need for public transportation.

The majority of the respondents ( $95 \%$ ) usually had a car available to them for use, but only 88.8 percent said they currently drive. Of the 29 respondents $(11.3 \%)$ who did not drive, 10 said their disability or age prevented them from driving; 6 preferred not to drive; 5 respondents did not learn how or never got a license; and 3 had medical conditions that prohibited them from driving. Of those who did not drive, 51.7 percent are disabled, compared to only 12.7 percent who were disabled and drove $\left(x^{2}=27.763 ; \mathrm{df}=1 ;\right.$ Prob. $\left.=0\right)$. Also, the reasons for not driving were related to the disability, with most of the disabled citing either medical advice or disability/age as why they did not drive $\left(\mathrm{x}^{2}=\right.$ 23.393; $\mathrm{df}=7$ Prob;. = 0.0015).

The majority of the respondents $(70.9 \%)$ rode a bus "more than a year ago," and only 5.8 percent rode a bus "this month." In addition, 65.5 percent rode a train or trolley more than one year ago, and only 2 percent rode one last 
month. About 18 percent of the respondents never rode a public transit bus. The corresponding percentages for door-to-door paratransit service are only 5.8 and 0 percent for riding more than a year ago, and this month, respectively. This low percentage for paratransit could be attributed to the fact that 92.3 percent of the respondents "never" used a paratransit door-to-door service, although 17.3 percent are disabled.

The overall results of the survey show that very few elderly are using public transportation, and that there is a vital need for public transit improvements to accommodate their needs for accessibility and mobility.

Abdel-Aty and Jovanis (1998) describe the initial investigation of the effect and acceptance of new technologies on the elderly. They found that some actions, such as walking or standing for some time, are considered impossible or extremely difficult to a considerable number of the elderly. They also report that the elderly generally take trips frequently.

Elderly females rated several actions/situations as impossible or difficult more often than males. They more likely required assistance from another person to get in and/or out of a standing car, truck, van, or transit vehicle. Females were more apt to not have a car available to them everyday, and they currently drove less than males. Females grocery shopped more frequently than males. Some indicated they were recently unable to make a grocery shopping trip because of a transportation problem. Also, more females noted that they were recently unable to keep a medical appointment because of a transportation problem. These results show several physical and transportation problems for elderly females, beside less car availability. In addition, the results point to a need to look more carefully at the transportation requirements of elderly females and to find solutions. This issue was confirmed when testing for the association between gender and the acceptance of transportation technologies addressed in the survey. Females consistently expressed willingness to use such systems and to use transit and/or paratransit systems.

\section{Advanced Transportation Systems}

The survey proposed five advanced transportation technologies to test the elderly's acceptance and potential use of such systems: 
- Onboard transit information

- Information kiosks

- Real-time paratransit services

- In-home information systems

- Personal information systems

The initial analysis shows that a real-time paratransit system would have the most effect on encouraging people to use paratransit. This is followed by the significant effect of in-home information on using real-time paratransit, and the positive effect of personal information systems also on using real-time paratransit. The results also indicate that the other systems encourage the use of transit or paratransit, but as mentioned above, real-time paratransit seems to be the most favored system if information is available.

The main objective of this study is to propose alternative technological solutions and to evaluate elderly travelers' perceptions and acceptance of such systems. In the survey, respondents were presented with the statement: "I am going to ask your opinion about the usefulness of several new transportation technologies." Then, questions related to each of the technologies were presented.

\section{On-Board Transit Information}

On-board transit information was described in the interview. Respondents were told:

Suppose transit buses and light-rail trains had information systems located on them. These would be electronic bulletin boards that could display information. The types of information would include:

- the name and location of the vehicle's next stop;

- the expected arrival time at the next stop;

- information about any transfers you might have to make to reach your final destination, including the expected arrival time of the next vehicle to which you would be transferring; and

- emergency phone numbers.

About 40 percent of the respondents who reported previously in the sur- 
vey that the last time they rode a public transit bus, transit train, or trolley was either "more than one year ago" or "never" (i.e., nonregular transit users), said that if on-vehicle information was available they would be more likely to use public transit.

As for respondents who said that the last time they rode public transit was less than one year ago (i.e., transit users), 60 percent said that on-vehicle information would make the trips they are already taking easier. About 30 percent said they would make more trips, and 10.6 percent indicated that such a system would have allowed them to make a trip that they recently missed (Figure 1).

\section{Information Kiosks}

Information kiosks were described as:

... an electronic bulletin board that not only displays information, but

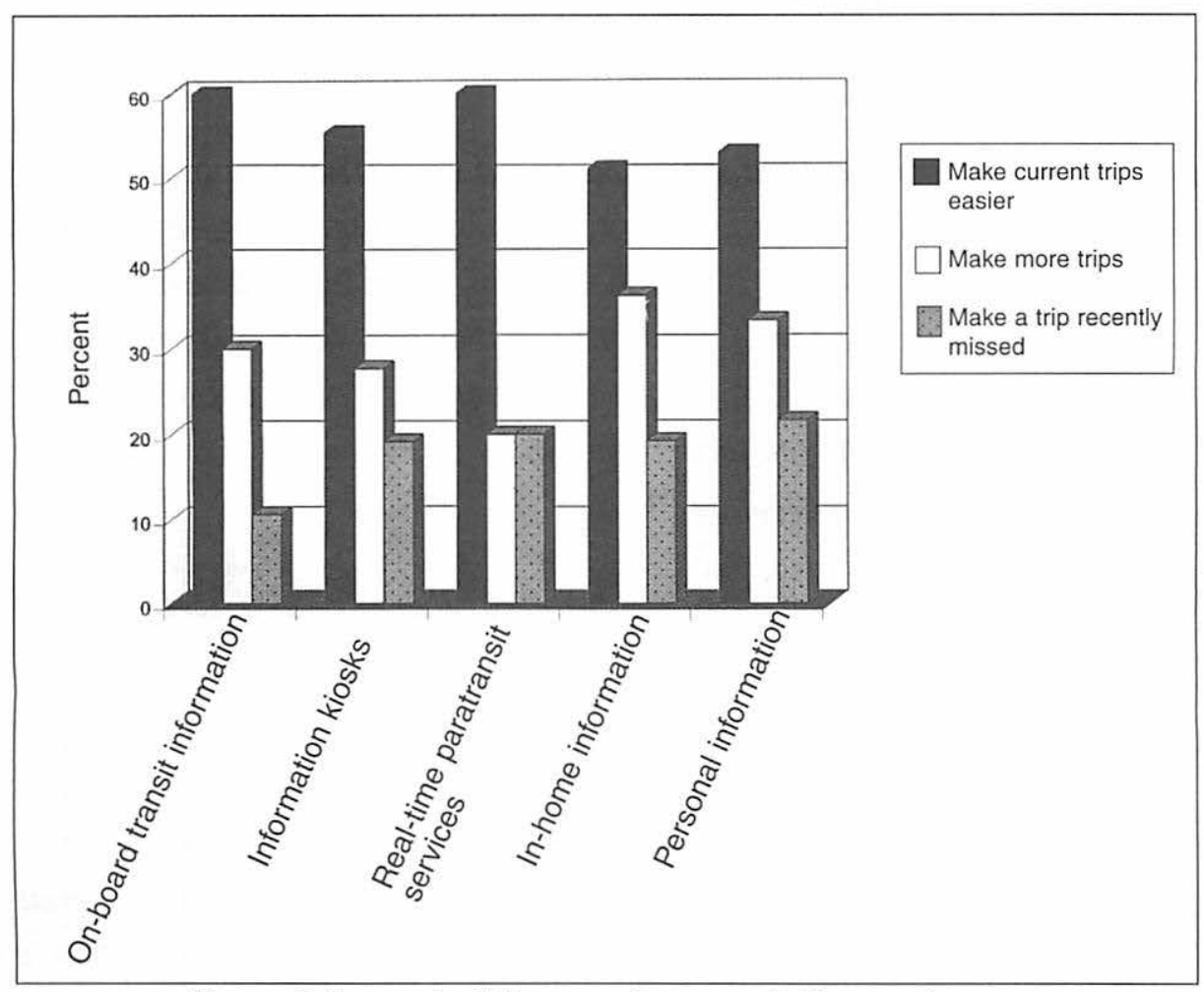

Figure 1. Impact of the new transportation systems 
also allows you to choose the type of information. The types of information available to you would be:

- the map of the transit route, including the stops nearest your actual destination,

- up-to-the-minute information on the expected arrival time of the next transit vehicle,

- the exact fare for your trip,

- the number and location of any transfers you might have to make to reach your destination,

- whether a wheelchair lift is available on the next arriving vehicle, and

- emergency phone numbers.

Suppose such information kiosks were located at light-rail transit stops and at major bus stops where transfers are made from one bus route to another.

About 44 percent of the nonregular transit users stated that if information kiosks were available, they would more likely use public transit. As for transit users, 55.3 percent said that information kiosks would make the trips they are already taking easier. About 27.7 percent said that they would make more trips, and 19.2 percent indicated that such a system would have allowed them to make a trip they recently missed (Figure 1).

\section{Real-Time Paratransit Services}

The interviewees were told:

Real-time paratransit is like the paratransit services you may have heard of or may now be using. A van would provide you with a "door-to-door" ride between your home and your destinations. You would likely be sharing this vehicle at least once in a while. Real-time paratransit systems would allow you to make a reservation on the day of a local trip you wanted to make, rather than requiring several days' advance reservation as with today's paratransit. 
About 56.9 percent of the nonregular paratransit users said that if realtime paratransit was available, they would more likely use paratransit. Of the paratransit users, 60 percent indicated that real-time paratransit service would make the trips they are already taking easier, 20 percent would make more trips, and 20 percent would have been able to make a trip that they recently missed (Figure 1).

Real-time paratransit is a door-to-door service, therefore it is convenient and does not require going to a transit stop that might be considered a difficulty by many senior travelers. Real-time paratransit is also attractive and efficient because it provides same-day service. Therefore, it is not surprising that respondents would be more enthusiastic about this service.

\section{In-Home Information Systems}

Respondents were told that in-home information systems:

...would deliver the same types of information to you at home as the information kiosk provides at transit stops. That is, it would tell you:

- the location of transit stops nearest your actual destination,

- a schedule of the regular arrival and departure times for transit vehicles at the stops nearest both the starting point and ending point of your trip,

- updated information on the actual expected arrival time of the next transit vehicle,

- the exact fare for your trip,

- the number and location of any transfers you might have to make to reach your destination, and

- whether a wheelchair lift is available on the next arriving vehicle.

In addition, the in-home system would provide you with information about ordinary paratransit that requires several days of advanced reservation, and real-time paratransit services such as we just discussed. This information might be delivered to you through your television or through a home computer. 
Respondents were asked if such a system would make them more likely to use public transit, paratransit, or real-time paratransit. About 43.6 percent, 45 percent, and 51.7 percent indicated that an in-home information system would make them more likely to use public transit, paratransit, and real-time paratransit, respectively. Compared to on-board and kiosk information, these percentages might show a slight preference for real-time paratransit for the elderly if provided with pretrip information.

As for respondents who indicated that the last time they rode public transit/paratransit was less than one year ago, 51 percent said that in-home information would make the trips they are already taking easier. About 36.2 percent said that they would make more trips, and 19.2 percent indicated that such a system would have allowed them to make a trip they recently missed (Figure 1).

\section{Personal Information Systems}

Interviewees were told that personal information systems:

...would provide you with all the information available to you in the inhome information system. However, it would be a small device that you could carry with you. It would tell you about:

- the location of transit stops nearest your actual destination,

- a schedule of the regular arrival and departure times for transit vehicles at the stops nearest both the starting point and ending point of your trip,

- updated information on the actual expected arrival time of the next transit vehicle,

- the exact fare for your trip,

- the number and location of any transfers you might have to make to reach your destination,

- whether a wheelchair lift is available on the next arriving vehicle, and

- whether any seats are available on the next arriving vehicle. 
Also, the personal system would provide you with information about ordinary paratransit that requires several days of advanced notice, and realtime paratransit services for which you could make reservations for doorto-door travel. You could access this information from wherever you happened to be within the city or region you live. Additionally, the personal information system would allow you to access a real-time paratransit provider from wherever you happen to be and make a reservation for later in the day.

About 40.1 percent of the respondents indicated that a personal information system would make them more likely to use public transit; 39.1, paratransit; and 48.3, real-time paratransit. Again, these percentages might show a slight preference of real-time paratransit for the elderly if provided with the personal information system. Also, it shows a slight preference for in-home information systems over personal information systems. This might be attributed to the fact that a personal information system could be perceived as a hitech gadget that is difficult to use. Such a resistance to new equipment is natural, particularly by the elderly.

As for transit/paratransit users, 52.9 percent said that a personal information system would make the trips they are already taking easier. About 33.3 percent said they would make more trips (about $65 \%$ said they would make such additional trips by transit, $29 \%$ using real-time paratransit, and only $6 \%$ by conventional paratransit). About 21.6 percent indicated that such a system would have allowed them to make a trip they recently missed (Figure 1).

\section{Evaluation of New Transportation Technologies}

In general, the results show that a real-time paratransit system would have the most effect on encouraging the elderly to use paratransit. This is followed by the significant effect of in-home information on using real-time paratransit, and the positive effect of personal information systems on also using real-time paratransit.

Figure 1 shows that both on-board information and real-time paratransit were chosen more frequently by current transit and paratransit users as the sys- 
tems that would make current trips easier. The figure also indicates that in-home information, followed by personal information systems, would have the greatest effect on encouraging the elderly to make more trips (increased mobility).

The respondents' perceptions of the usefulness of each of the information systems is presented in Figure 2. Real-time paratransit was seen as the most useful by 29.5 percent of the respondents. This was followed by personal information systems (26\%) and in-home information systems (26\%). Information kiosks and on-board transit information were chosen by 12.8 percent and 5.4 percent of the respondents, respectively.

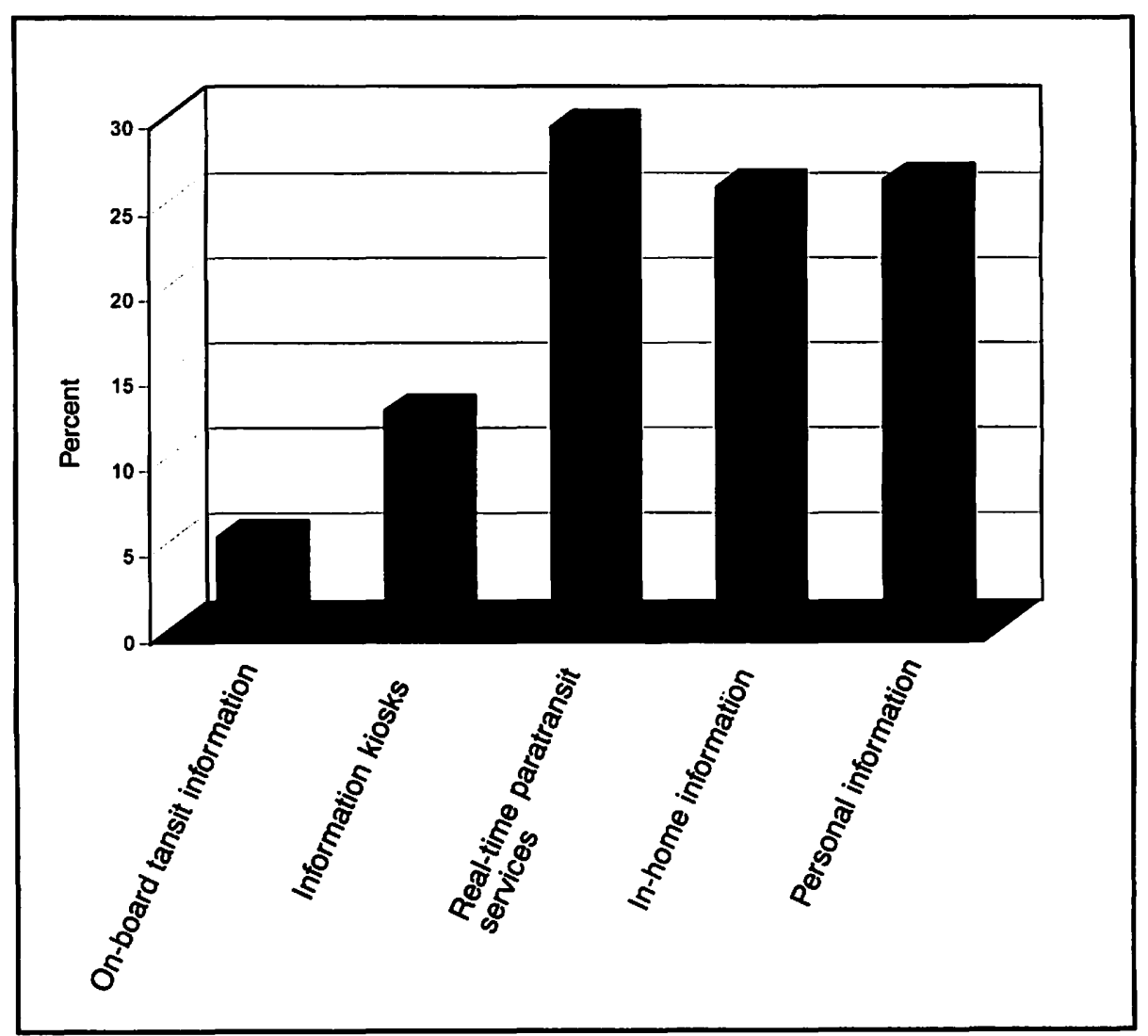

Figure 2. Respondents' selection of the most useful transportation technology 


\section{Modeling Seniors' Acceptance of Advanced Transportation Technologies}

This section described a modeling effort (in a multivariate context) of the elderly's acceptance of the different advanced transit systems proposed in the survey. The purpose of this modeling effort was to identify the factors that influence the elderly's choice to use transit or paratransit, given the availability of one of the proposed advanced systems. The approach pursued here uses the binary probit model formulation. It assumes that an individual's perceived utility for a specific choice is a function of the perceived attributes of the alternative and the individual's characteristics.

\section{Methodological Approach}

The random utility theory was used in estimating the models. The theory assumes that an individual's choice is based on the utility gain experienced by the individual for a particular choice. If an individual perceives a certain gain by using a certain mode of travel, then the perceived utility of this choice is larger than that of the alternative. A binary probit model was used to estimate the respondent's likelihood of using transit/paratransit if certain a new system was available as opposed to the alternative of not choosing this mode.

Suppose $\varepsilon_{i n}$ and $\varepsilon_{j n}$ are both normal with zero means and variances $\sigma^{2}{ }_{i}$ and $\sigma^{2}$, respectively. Suppose further that they have covariance $\sigma_{i j}$. Under these assumptions, the term $\varepsilon_{i n}-\varepsilon_{j n}$ is also normally distributed with mean zero but with variances $\sigma^{2} i+\sigma^{2}{ }_{j}-2 \sigma_{i j}=\sigma^{2}$. This result can be used to solve for the choice probabilities as follows (Ben-Akiva and Lerman 1985; Daganzo 1979):

$$
\begin{aligned}
& P_{n}(i)=\operatorname{Pr}\left(\varepsilon_{j n}-\varepsilon_{i n} \leq V_{i n}-V_{j n}\right) \\
& =\int_{\varepsilon}^{V_{i n}}-V_{j n} \frac{1}{\sqrt{2 \pi \sigma}} \exp \left[\frac{-1}{2}\left(\frac{\varepsilon^{2}}{\sigma}\right)\right] d \varepsilon, \sigma>0, \\
& =\frac{1}{\sqrt{2 \pi}} \int_{-\infty}^{\left(V_{i n}-V_{j n}\right) / \sigma} \exp \left[\frac{-1}{2} u^{2}\right] d u=\Phi\left(\frac{V_{i n}-V_{j n}}{\sigma}\right),
\end{aligned}
$$

where: $\Phi($ ) denotes the standardized cumulative normal distribution. 
In the case where $V_{i n}=\beta^{\prime} x_{i n}\left(\beta^{\prime}\right.$ is the vector of estimated coefficients, and $\mathrm{x}_{i n}$ explanatory variables) and $V_{j n}=\beta^{\prime} \mathrm{x}_{j n}$,

$$
P n(i)=\Phi\left(\frac{\beta^{\prime}\left(X_{i n}-X_{j n}\right)}{\sigma}\right)
$$

In this case, $1 / \sigma$ is the scale of the utility function, which can be set to an arbitrary positive value, usually 1 . The binary probit choice probabilities depend only on $\sigma$, not on $\sigma_{i}^{2}, \sigma 2_{j}$, and $\sigma_{i j}$. Thus, the variances and covariance of the two disturbances are irrelevant to the choice probabilities.

\section{Estimation Results}

In all, seven models were estimated to address the acceptance of the ITS systems proposed in this study. Only four complete models are presented due to space limitations. Table 1 summarizes the results of all seven.

Information Kiosks. A model of whether a respondent would be more likely to use public transit, if information kiosks were available, was estimated using the binary probit formulation (Table 2). Numerous variable combinations were attempted before reaching the final model presented in Table 2. Although not all the variables that were entered into the final model are significant at the 95 percent confidence level (i.e., $t$-stat. $\geq 1.96$ ), all the variables had the appropriate sign, and had a rational interpretation. Also, this combination of variables achieved the best overall fit of the model.

The model shows that females are more likely to use transit if information kiosks are available. This might be an expected finding since earlier results indicated that females have greater transportation problems (Abdel-Aty and Jovanis $1998)$. Middle-income respondents $(\$ 20,000-\$ 49,999)$ are more likely to use transit. This group is probably educated and willing to use information. Respondents with lower incomes might be using transit already, while respondents with higher incomes are not ready to change their current mode (private car). The respondent's age was found to affect the choice to use transit. The younger group of elderly (65-69 years old) are more likely to use transit, while the older-age group (more than age 80) are less likely to use transit given the availability of information kiosks when compared to the 65- to 69-year-old 


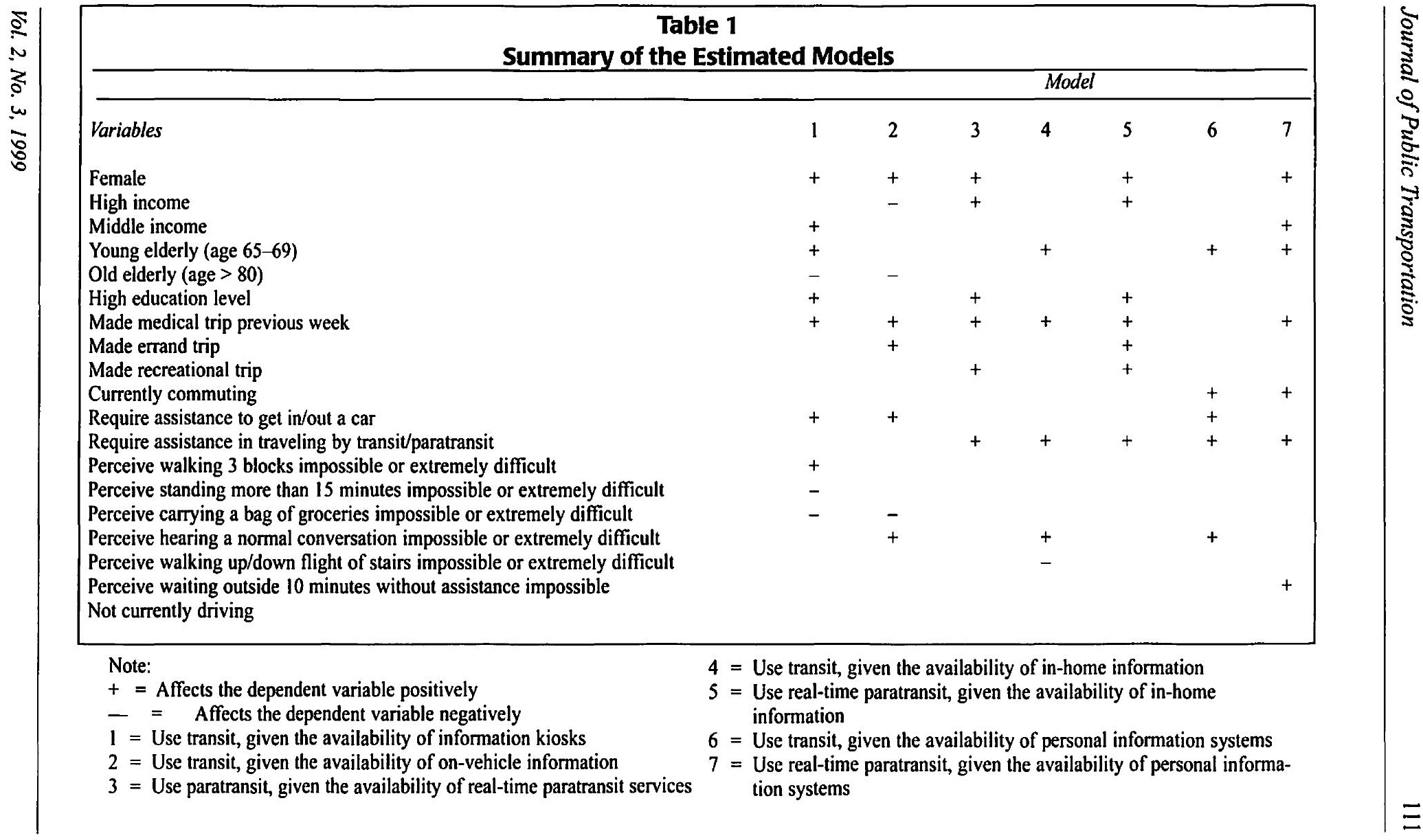




\begin{tabular}{|c|c|c|}
\hline \multicolumn{3}{|c|}{$\begin{array}{c}\text { Table } 2 \\
\text { Probit Model of the Likelihood of Using Transit, Given Information } \\
\text { Kiosks Are Available }\end{array}$} \\
\hline & $\beta$ & t-statistic \\
\hline$\beta_{0}$ Use transit constant & -0.652 & -3.428 \\
\hline$X_{1}$ Female dummy variable & 0.376 & 2.116 \\
\hline $\begin{array}{l}X_{2} \text { Middle-income dummy variable } \\
\text { (1 if income } \$ 20,000-\$ 49,999)\end{array}$ & 0.299 & 1.726 \\
\hline $\begin{array}{l}X_{3} \text { Younger-age dummy variable } \\
\text { (1 if age } 65-69,0 \text { otherwise) }\end{array}$ & 0.318 & 1.581 \\
\hline $\begin{array}{l}X_{4} \text { Older-age dummy variable } \\
\text { (1 if age } \geq 80,0 \text { otherwise) }\end{array}$ & -0.415 & -1.543 \\
\hline $\begin{array}{l}\mathrm{X}_{5} \text { High education-level dummy variable } \\
\text { (1 if graduate degree, } 0 \text { otherwise) }\end{array}$ & 0.822 & 2.910 \\
\hline $\mathrm{X}_{6}$ Require assistance to get in/out of car & 0.514 & 1.411 \\
\hline $\mathrm{X}_{7}$ Made clinic/hospital/medical trip last week & 0.248 & 1.390 \\
\hline $\begin{array}{l}\mathrm{X}_{8} \text { Perceive walking } 3 \text { blocks without resting as } \\
\text { impossible or extremely difficult, dummy variable }\end{array}$ & 0.580 & 2.029 \\
\hline $\begin{array}{l}\mathrm{X}_{9} \text { Perceive standing for more than } 15 \text { minutes } \\
\text { impossible or extremely difficult, dummy variable }\end{array}$ & -0.652 & -1.893 \\
\hline $\begin{array}{l}\mathrm{X}_{10} \text { Perceive carrying a bag of groceries as } \\
\text { impossible or extremely difficult, dummy variable }\end{array}$ & -0.525 & -1.202 \\
\hline $\begin{array}{l}\text { Summary Statistics } \\
\text { Log likelihood at } 0=-187.0304 \\
\text { Log likelihood at convergence }=-156.8336 \\
\text { Likelihood ratio index around } 0=0.161 \\
\text { Number of observations }=248\end{array}$ & & \\
\hline
\end{tabular}

Note: Variables are defined for the alternative of choosing to use transit if the information kiosks were available. 
group. As travelers age, regular transit buses might be difficult to use, even if information was available. Respondents who have a graduate degree are also more likely to use transit. The well-educated elderly are more apt to use different technologies including information kiosks.

Elderly people who require assistance to get in/out of a car are more likely to use transit, indicating their desire for more independence. Those who responded that they made a medical-related trip in the week prior to the survey, are more likely to use transit given the availability of information kiosks. This was the only trip purpose found significant, indicating the necessity of such trips and that the elderly need reliable transportation for such trips.

Several perception-related variables representing the respondents' physical capabilities were entered into the model. Respondents perceiving walking three blocks to be impossible or extremely difficult, are more likely to choose transit, given the availability of information kiosks. These respondents probably associate their capabilities with the modes or transportation systems they currently use, and their need to a system that facilitates the effort they exert. However, respondents that perceive standing for 15 minutes and/or carrying a bag of groceries as impossible or extremely difficult are less likely to use transit.

On-board Transit Information. Table 3 presents a binary probit model of whether the respondents are more likely to use public transit if on-board vehicle information systems were available. The estimation results show, as in the previous model, that females are more likely to use transit (although this variable is not significant at the $95 \%$ level as in the previous model). Highincome respondents (household income between $\$ 70,000-\$ 89,999$ ) are less likely to use transit, given the availability of on-board information. Highincome respondents are probably not willing to change their mode of travel from the private car to transit because they have the financial ability to have a good car and assistance if needed. Also, the older group (more than 80 years) is less likely to use transit, possibly because of the perceived difficulty associated with using this mode (i.e., walking to bus stops, waiting, etc.).

As in the previous model, if respondents require assistance to get in or out of private vehicles, then they would be more likely to use transit, although it is 


\begin{tabular}{|c|c|c|}
\hline \multicolumn{3}{|c|}{$\begin{array}{c}\text { Table } 3 \\
\text { Probit Model of the Likelihood of Using Transit Given the Availability } \\
\text { of On-Vehicle Information }\end{array}$} \\
\hline & $\beta$ & t-statistic \\
\hline$\beta_{0}$ Use transit constant & -0.563 & -2.389 \\
\hline $\mathrm{X}_{1}$ Female dummy variable & 0.267 & 1.570 \\
\hline$X_{2}$ High-income dummy variable ( 1 if income $\$ 70,000-\$ 89,999$ ) & -0.827 & -1.363 \\
\hline$X_{3}$ Older-age dummy variable ( 1 if age $\geq 80,0$ otherwise) & -0.405 & -1.490 \\
\hline $\mathrm{X}_{4}$ Require assistance to get in/out of a car & 0.783 & 2.117 \\
\hline $\mathrm{X}_{5}$ Made clinic/hospital/medical trip last week & 0.246 & 1.397 \\
\hline $\begin{array}{l}\mathrm{X}_{6} \text { Perceive carrying a bag of groceries as impossible or } \\
\text { extremely difficult, dummy variable }\end{array}$ & -1.175 & -2.463 \\
\hline \multicolumn{3}{|l|}{$\mathrm{X}_{7}$ Perceive hearing a normal conversation as impossible or extremely } \\
\hline difficult, dummy variable & 0.675 & 1.514 \\
\hline $\mathrm{X}_{8}$ Made an errand trip last week & 0.260 & 1.222 \\
\hline $\begin{array}{l}\text { Summary Statistics } \\
\text { Log likelihood at } 0=-191.1275 \\
\text { Log likelihood at convergence }=-158.3695 \\
\text { Likelihood ratio index around } 0=0.171 \\
\text { Number of observations }=247\end{array}$ & & \\
\hline
\end{tabular}

Note: Variables are defined for the alternative of choosing to use transit if on-vehicle information was available.

unlikely that a senior traveler that requires assistance would use transit. This variable has consistently been significant, probably indicating the high level of frustration of this group of elderly, and the need to address their mobility problems. Also, respondents that made a medical-related trip or ran an errand during the week prior to the survey were more likely to choose transit. Although the running errand variable is only significant at the 78 percent level, it was included because it improved the overall fit of the model. Therefore, medical trips, as discussed above, are considered the most important type of trip for the elderly.

Perceiving hearing a normal conversation as impossible or extremely difficult affects positively the likelihood of using transit, given the availability of on-board information. This indicates that the elderly with communication 
problems would seek information because it saves them the embarrassment of asking the driver or another passenger for help. Perceiving carrying a bag of groceries as impossible or extremely difficult negatively affects the likelihood of using transit (i.e., if carrying the groceries is a problem, then riding the bus is a problem).

Real-Time Paratransit Services. A binary probit model of whether respondents are more likely to use paratransit if real-time paratransit services were available was estimated. The estimation results show, as in the previous models, that females are more likely to use paratransit. High-income respondents (household income greater than $\$ 70,000$ ) are more likely to use paratransit given the availability of real-time systems. In comparing the income variable with the previous two models, high-income respondents were shown to prefer paratransit over transit, probably a tendency to use more private modes of transportation.

Respondents with a graduate or four-year college degree are more likely to use real-time paratransit. Also, respondents who require assistance in traveling by transit or paratransit are more likely to consider real-time paratransit.

In terms of trip type, making a medical trip the week before the survey positively influences the likelihood of using paratransit. This is consistently a significant variable in all the estimated models, indicating the importance of this type of trip. Making recreational/leisure trips, although marginally significant in this model, shows that real-time paratransit could improve the elderly's mobility and hence encourage those who usually make such trips to use real-time paratransit.

In-Home Information Systems. Two models were developed to investigate the potential effect of in-home information systems. The first is a binary probit model of whether respondents would be more likely to use public transit if in-home information systems were available (Table 4). The second is a binary probit model of whether respondents would be more likely to use realtime paratransit if in-home information systems were available (Table 5). The first model is the only model estimated that does not show any gender effect. All the previous models showed that females have a likelihood to use transit or 


\section{Table 4}

\section{Probit Model of the Likelihood of Using Public Transit If In-Home Information Was Available}

\begin{tabular}{lrr}
\hline & $\beta$ & $t$-statistic \\
\hline$\beta 0$ Use transit constant & -0.413 & -3.358 \\
$X_{1}$ Younger-age dummy variable (1 if age 65-69, 0 otherwise) & 0.373 & 1.912 \\
$X_{2}$ Respondent not currently driving a vehicle & -0.487 & -1.563 \\
$X_{3}$ Made clinic/hospital/medical trip last week & 0.318 & 1.812 \\
$X_{4}$ Perceive walking up or down a flight of stairs as impossible or extremely & & \\
difficult, dummy variable & -0.933 & -2.584 \\
$X_{5}$ Perceive hearing what is said in a normal conversation as impossible or & & \\
extremely difficult, dummy variable & 1.041 & 2.333 \\
$X_{6}$ Require assistance while traveling by transit or paratransit & 0.815 & 2.386 \\
& & \\
Summary Statistics & & \\
Log likelihood at $0=-194.2201$ & \\
Log likelihood at convergence $=-158.4135$ & \\
Likelihood ratio index around $0=0.184$ & \\
Number of observations $=249$ & \\
\hline
\end{tabular}

Note: Variables are defined for the alternative of choosing to use transit if in-home information was available.

paratransit given the availability of information, and this was attributed to their transportation difficulties. The second model showed a significant likelihood of females using real-time paratransit. This might indicate that in the event inhome information was available, females prefer paratransit over transit.

The second variable (not driving a vehicle) in the first model (Table 3) unexpectedly has a negative sign, indicating that respondents who currently do not drive are less likely to use transit. However, a closer examination of this group reveals that it is relatively small (29 respondents), and that the respondents probably have physical problems that prevent them from driving. Thus, it can be concluded that physical problems could make transit use difficult as well. Both models show that respondents requiring assistance while traveling by transit or paratransit would be more likely to use the proposed system.

In both models, making a medical-related trip the previous week increased the likelihood of using the proposed system. However, in the second model, making a recreational/leisure or errand trip was entered into the model. 


\begin{tabular}{|c|c|c|}
\hline \multicolumn{3}{|c|}{$\begin{array}{l}\text { Table } 5 \\
\text { Probit Model of the Likelihood of Using Real-Time Paratransit } \\
\text { if In-Home Information Was Available }\end{array}$} \\
\hline & $\beta$ & t-statistic \\
\hline$\beta_{0}$ Use real-time paratransit constant & -0.873 & 3.680 \\
\hline $\mathrm{X}_{1}$ Female dummy variable & 0.308 & 1.863 \\
\hline $\begin{array}{l}X_{2} \text { High level of education dummy variable } \\
\text { ( } 1 \text { if graduate or } 4 \text {-year college degree, } 0 \text { otherwise) }\end{array}$ & 0.450 & 1.625 \\
\hline $\mathrm{X}_{3}$ Made recreational/leisure trip last week & 0.227 & 1.250 \\
\hline $\mathrm{X}_{4}$ Made clinic/hospital/medical trip last week & 0.367 & 2.140 \\
\hline $\mathrm{X}_{5}$ Made an errand trip last week & 0.300 & 1.472 \\
\hline $\mathrm{X}_{6}$ Require assistance while traveling by transit/paratransit & 0.729 & 2.433 \\
\hline$X_{7}$ High-income dummy variable ( 1 if income $\$ 70,000-\$ 89,999$ ) & 0.635 & 1.089 \\
\hline $\begin{array}{l}\text { Summary Statistics } \\
\text { Log likelihood at } 0=-193.5583 \\
\text { Log likelihood at convergence }=-165.5845 \\
\text { Likelihood ratio index around } 0=0.145 \\
\text { Number of observations }=256\end{array}$ & & \\
\hline
\end{tabular}

Note: Variables are defined for the alternative of choosing to use real-time paratransit if in-home information was available.

This indicates that real-time paratransit might increase the elderly's mobility by allowing them to make a variety of trip types.

Respondents perceiving walking up or down a flight of stairs as impossible or extremely difficult are less likely to use transit. Respondents who perceive what is said in a normal conversation as impossible or extremely difficult are more likely to use transit if in-home information was available. In this case, in-home information would help these respondents avoid the problem of communicating with others to ask transit-related questions.

Table 3 shows that the younger elderly (age 65-69) are more likely to use transit than older-age groups, given in-home information. Table 5 shows that welleducated respondents (graduate or four-year college degree) are more likely to use real-time paratransit, if in-home information was available. This group is usually familiar with computers, and one of the sources of in-home information would be computers. Also, high-income respondents $(\$ 70,000-\$ 89,999)$ are more likely to use real-time paratransit. 
Personal Information Systems. Two models were developed to investigate the potential effect of personal information systems. The first is a binary probit model of whether respondents would be more likely to use public transit if personal information systems were available. The second is a binary probit model of whether respondents would be more likely to use real-time paratransit if personal information systems were available.

The models are similar to those developed for in-home information (Tables 4 and 5). The significant variables entered in the first model were: younger elderly dummy variable (65-69), requiring assistance to travel, perception of the difficulty of hearing, and commute dummy variable. The second model showed significance of the female dummy variable, younger elderly, requiring assistance, commute, middle income, and medical trips on the likelihood of using real-time paratransit, given the availability of personal information systems.

\section{Summary and Conclusions}

A CATI survey of the elderly, conducted in August 1996, targeted a random sample of the senior population in the Sacramento area. The survey was limited to respondents 65 years old and above and yielded a sample of 260 respondents. The main objectives of the study were to define the characteristics and travel behavior of senior citizens, and to test their acceptance of different new transportation technologies and the technologies' potential for improving their mobility.

A previous study (Abdel-Aty and Jovanis 1998) described the sample and presented the survey design and general descriptive statistics. The results illustrated that the elderly generally perform trips frequently, and pointed to the importance of improving transportation to meet the needs of the elderly.

The survey proposed five advanced transit technologies to test the elderly's acceptance and potential use of such systems.

The binary probit model formulation was used to estimate the elderly's potential use of such systems. Those surveyed were asked whether they would use transit (or paratransit) if one of the suggested technologies was available. The estimation results showed that females consistently try to find solutions to 
their transportation problems. Being a female was always a significant variable in choosing to use transit (or paratransit) when any type of information was available (Table 1). However, if the information system is available for both transit and paratransit (in-home and personal information), females tend to choose real-time paratransit. Sensitivity analysis shows that the gender effect is strongest in the information kiosk and the real-time paratransit models. Highincome respondents were more likely to use real-time paratransit, whether this service was provided by itself or with in-home or personal information. However, the level of significance is higher and the effect of this variable is stronger if the service is provided without personal information. High-income respondents appear satisfied with the service itself without any information. Females and high-income elderly are two potential sociodemographic market groups for real-time paratransit.

The younger group of elderly (age 65-69) is more likely to use transit if information kiosks, in-home information, or personal information is available. However, this group is also more likely to use real-time paratransit if personal information is available. The effect is profound for using transit when in-home or personal information is provided, indicating a preference for transit over paratransit for the younger elderly. This result shows the group's acceptance of information systems that could be perceived as a new device or require familiarity with computers. Well-educated respondents are more likely to use paratransit if this service is available, or if in-home information is available. They are also likely to use transit given the availability of information kiosks (Table 1).

Medical trips are extremely important for the elderly. The models showed that those who made a medical trip the week before the survey were accepting any proposed new transportation system and willing to use it. However, the effect was more significant for real-time paratransit and real-time paratransit associated with in-home information. Respondents who are still commuting generally accepted personal information systems.

Respondents' perceptions of the difficulty of some actions/situations were also significant in the models. One of the most important situations is the ability to hear what is said in a normal conversation. Respondents who considered 
this action as impossible or extremely difficult were more likely to use transit if on-board, in-home, or personal information systems were available (Table 1). This variable indicates that the communication problem experienced by some elderly travelers could be avoided by providing transportation information.

The survey and the analysis illustrated the elderly's difficulties and problems with transportation. They also showed the important potential of several transit technologies to increase the mobility and alleviate the transportation difficulties of the elderly population. The results illustrate the willingness of many groups of senior travelers to use new transportation systems in an attempt to reduce their travel dependence and problems. The study demonstrates that seniors might be willing to change their primary mode of travel from the private vehicle to other public modes if better systems were available.

\section{References}

Abdel-Aty, M., and P. Jovanis. 1998. A survey of the elderly: An assessment of their travel characteristics. Paper presented at the 77th Annual Meeting of the Transportation Research Board, Washington DC (Reprint No. 980001).

Ben-Akiva, M., and S. Lerman. 1985. Discrete choice analysis: Theory and application to travel demand. Cambridge, MA: The MIT Press.

Daganzo, C. 1979. Multinomial probit: The theory and its application to demand forecasting. New York: Academic Press Inc.

Geehan, T., and L. Suen. 1993. User acceptance of advanced traveler information systems for the elderly and disabled travelers in Canada. IEEE-IEE Vehicle Navigation and Information Systems Conference, Ottawa, VNIS '93.

Guthrie, B., and A. Phillips. 1994. Market estimates of Intelligent Transportation Systems for seniors and people with disabilities. Proceedings of the First World Congress on Applications of Transport Telematics and Intelligent VehicleHighway Systems, Paris, France.

Lago, A., and J. Burkhardt. 1980. Predictive models of the demand for public transportation services among the elderly. Transportation Research Record 784, 21-27.

Parolin, B. 1988. Travel mode choice behavior and physical barrier constraints among the elderly and handicapped: An examination of travel mode preferences. Transportation Research Record 1170, 19-28. 
Schweiger, C., and J. McGrane. 1994. The challenge for developing and implementing advanced public transportation systems for elderly and disabled customers. Proceedings of the First World Congress on Applications of Transport Telematics and Intelligent Vehicle-Highway Systems, Paris, France.

Suen, L., and J. Parviainen. 1993. Advanced travel accessibility systems for the elderly and disabled: A conceptual framework. IEEE-IEE Vehicle Navigation and Information Systems Conference, Ottawa, VNIS '93.

Suen, L., and U. Rutenberg. 1994. Advanced transportation information systems for elderly and disabled travelers in transportation terminals. Proceedings of the First World Congress on Applications of Transport Telematics and Intelligent VehicleHighway Systems, Paris, France.

Transportation Research Board. 1988. Transportation in an aging society: Improving mobility and safety for older persons. Special Report 218.

U.S. Department of Transportation. 1992. Travel behavior issues in the '90s, 1990 Nationwide Personal Transportation Survey, Washington, DC: Federal Highway Administration.

Witkowski, J., and T. Buick. 1985. Travel behavior of residents of retirement communities, Transportation Research Record 1018, 13-22.

\section{About the Author}

Mohamed A. AbDel-ATY is an assistant professor of transportation engineering at the University of Central Florida. He received a Ph.D. in transportation engineering from the University of California at Davis in 1995. 